\title{
Relationship Between Vegetation Microwave Optical Depth and Cross-Polarized Backscatter From Multiyear Aquarius Observations
}

\author{
Kathrina Rötzer, Carsten Montzka, Member, IEEE, Dara Entekhabi, Fellow, IEEE, \\ Alexandra G. Konings, Member, IEEE, Kaighin A. McColl, Member, IEEE, Maria Piles, Member, IEEE, \\ and Harry Vereecken
}

\begin{abstract}
Soil moisture retrieval algorithms based on passive microwave remote sensing observations need to account for vegetation attenuation and emission, which is generally parameterized as vegetation optical depth (VOD). This multisensor study tests a new method to retrieve VOD from cross-polarized radar backscattering coefficients. Three years of Aquarius/SAC-D data were used to establish a relationship between the cross-polarized backscattering coefficient $\sigma_{\mathrm{HV}}$ and VOD derived from a multitemporal passive dual-channel algorithm $\left(\operatorname{VOD}_{\mathrm{MT}}\right)$. The dependence of the correspondence is analyzed for different land use classes. There are no systematic differences in the slope for woody versus nonwoody vegetation, resulting in a strong correlation (80\% explainedvariance) and a global linear relationship when all classes are combined. The relationship is stable over the years of observations. The comparison of the Aquarius-derived VOD $_{M}$ T to Soil Moisture and Ocean Salinity's multi-angular VOD estimates shows similar spatial patterns and temporal behavior, evident in high correlations. However, VOD $_{M T}$ has considerably higher mean values, but lower dynamic range globally. Most of the differences can be attributed to differences in instrument sampling. The main result of this study, a relationship between backscatter and VOD, will permit high-resolution mapping of VOD with synthetic aperture radar measurements. These maps allow future studies of scaling and heterogeneity effects of vegetation on soil moisture retrieval at the coarser scales of land microwave radiometry. The study shows that VOD based on passive measurements and predicted by active measurements are comparable globally and that the breakdown by land cover classification does not affect the relationship appreciably.
\end{abstract}

Manuscript received December 24, 2016; revised May 6, 2017; accepted June 3,2017 . This work was supported in part by the Helmholtz Alliance on "Remote Sensing and Earth System Dynamics" and in part by the BelSpo STEREO III Programme with the HYDRAS + project. The work of K. A. McColl was supported by the National Science Foundation's Graduate Research Fellowship Program. (Corresponding author: Kathrina Rötzer.)

K. Rötzer, C. Montzka, and H. Vereecken are with the Institute of Bio- and Geosciences: Agrosphere (IBG 3), Forschungszentrum Jülich GmbH, Jülich 52428, Germany (e-mail: k.roetzer@fz-juelich.de; c.montzka@fz-juelich.de; h.vereecken@fz-juelich.de).

D. Entekhabi and K. A. McColl are with the Department of Civil and Environmental Engineering, Massachusetts Institute of Technology, Cambridge, MA 02139 USA (e-mail: darae@mit.edu; kmccoll@mit.edu).

A. G. Konings is with the Department of Earth System Science, Stanford University, Stanford, CA 94305 USA (e-mail: konings@ mit.edu).

M. Piles is with the Image Processing Laboratory, Universitat de València, València 46980, Spain (e-mail: maria.piles@gmail.com).

Color versions of one or more of the figures in this paper are available online at http://ieeexplore.ieee.org.

Digital Object Identifier 10.1109/JSTARS.2017.2716638
Index Terms-Microwave measurements, microwave radiometry, radar measurements, remote sensing, vegetation mapping.

\section{INTRODUCTION}

B OTH active and passive microwave remote sensing of soil moisture must account for the vegetation covering the soil in the design and implementation of soil moisture retrieval algorithms. Vegetation cover affects the passive microwave signal through attenuation of the signal emitted from the soil and through emission of radiation directly from the vegetation (which is itself attenuated as it travels through the vegetation layer) [1]. In active microwave remote sensing, vegetation disturbs the signal twice, on its way from the sensor to the ground and when it is sent back from the soil to the sensor through surface scattering by attenuation. Multiple interactions and vegetation volume scattering also affect the return signal [2]. The influence of vegetation on the microwave signal has to be quantified in any algorithm for soil moisture retrieval. The focus of this study is the microwave vegetation optical depth (VOD) that is a required parameter for soil moisture retrieval based on passive microwave remote sensing. Since space-borne L-band radiometry of the Earth's surface is coarse resolution (limited by the dimension of the antennas), the heterogeneity of the surface vegetation cover introduces errors in retrieval algorithms. In this study, we establish a relationship between VOD and radar backscatter which can be used to map this important vegetation property at higher resolutions associated with microwave radar sensors.

The most common retrieval algorithms for passive microwave sensors are based on the $\tau-\omega$ model [3], where the vegetation is quantified by the microwave optical depth of vegetation $\tau$ and effective single scattering albedo $\omega$. While the single scattering albedo describes the scattering effects in a canopy, VOD or $\tau$ describes the attenuation of the soil radiation through the canopy layer and is an important parameter for the characterization of the emission from canopy itself. Its value is strongly affected by vegetation water content (VWC) [4] through the vegetation dielectric constant; other influencing factors are the geometrical structure of the vegetation and microwave polarization and frequency [1]. VOD is known to be linearly proportional to VWC, with an empirical constant of proportionality known as 
the $b$-parameter, which varies according to frequency, vegetation geometry, and possibly polarization [5], [6].

Several studies have sought to determine microwave VOD from optical vegetation indices such as leaf area index (LAI) [7] or normalized difference vegetation index (NDVI) [8]. However, these vegetation indices from optical remote sensing are limited by the lack of direct correspondence between optical and microwave properties of the vegetation cover. In order to infer VOD from VWC or directly from an optical index, for example from LAI, empirical relationships are used. As a result of their empirical nature, the reliability of microwave VOD derived using optical data is in question. Unlike VOD, optical estimates of vegetation opacity become saturated in the presence of high vegetation density [9]. Furthermore, optical indices such as NDVI are insensitive to the woody components of plants [10], while VOD is also influenced by nongreen components such as woody stems and branches [11]. Therefore, there may not actually be a one-to-one relationship between the two variables. Moreover, indices calculated from red and near-infrared bands can be contaminated by atmospheric effects such as aerosols, water vapor, or clouds [12], in particular in tropical moist regions. In dry regions, optical vegetation indices can also be affected by atmospheric dust [13]. Optical data furthermore can only be collected in the presence of solar illumination and during daytime.

Nevertheless, optical vegetation indices are used in the algorithms of several currently available soil moisture products. The soil moisture product of the Aquarius/SAC-D satellite [14] is derived from radiometer measurements in a single channel algorithm [15]. There, VOD is estimated from VWC, which is inferred from MODIS NDVI. The current baseline algorithm for passive soil moisture retrieval of the new instrument for soil moisture monitoring, the soil moisture active passive (SMAP) satellite [16], is also based on VOD from VWC established with MODIS NDVI climatology [17].

In the soil moisture and ocean salinity (SMOS) [18] level 2 processor for soil moisture, VOD is derived through a two-parameter retrieval method using multi-angular and dualpolarization observations. However, as initialization values for the retrieval and where there are not enough angular measurements, VOD is estimated based on LAI taken from ECOCLIMAP [19].

Several methods have been used to estimate VOD based on microwave measurements that do not span multiple angles. These methods mostly rely on the joint use of both $\mathrm{H}$ - and $\mathrm{V}$ polarized radiometer observations in order to retrieve both the surface contribution and VOD simultaneously [20]. It is most common to use a single snapshot of $\mathrm{H}$ - and V-polarized observations to estimate the VOD and soil moisture. In the past, the microwave polarization difference index, a vegetation index of radiometer brightness temperatures, has been used for the estimation of microwave optical depth together with soil moisture in the land parameter retrieval model (LPRM) [21]. This model is used, for example, for the retrieval of soil moisture from passive microwave sensors for the ESA CCI product [22]. Tian et al. [23] found that VOD retrieved from LPRM shows an increased sensitivity to information on the woody plant foliage and is also found to be less affected by saturation effects compared to NDVI in the green parts of a West African dryland area. However, since the $\mathrm{H}$ - and V-polarized measurements are correlated, the pair of brightness temperatures does not contain enough information to allow retrieval of the two independent parameters soil moisture and VOD in the algorithm forward model in a robust fashion [24]. Alternatively, a time series of observations can be used, coupled with the assumption that VOD dynamics are likely to change more slowly than soil moisture [25].

In this study, we compare VOD derived through a multitemporal algorithm $\left(\mathrm{VOD}_{\mathrm{MT}}\right)$ and the multi-angular VOD from the

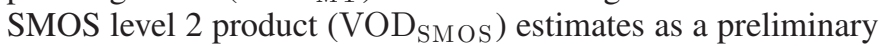
step. However, the goal is to relate VOD to active backscatter measurements for the reasons stated above. All factors underlying VOD, such as VWC and scattering, are characterized through active microwave remote sensing. Unlike optical measurements, active microwave remote sensing is not affected by solar illumination, clouds, and weather conditions. Radar measurements are sensitive to the same VWC and structural parameters as passive measurements. Active microwave remote sensing can also achieve higher resolution mapping of global land surfaces. Several prior studies investigated the relationship of active microwave observations with biophysical parameters such as LAI and VWC. These studies use backscattering coefficients or indices based on them (e.g., [26]-[30]).

Rowlandson and Berg [31] analyzed the correlation of several backscattering coefficients and backscattering ratios to VWC and LAI over soybean, winter wheat, and spring wheat fields. They found highest correlations of both, VWC and LAI, with the HV backscattering coefficient ( $\left.\sigma_{\mathrm{HV}}\right)$. Jiao et al. [32] found a strong correlation between $\sigma_{\mathrm{HV}}$ and LAI, mainly for corn in Lband and C-band, and a slightly lower correlation for soybeans. Ferrazzoli et al. [33] found that $\sigma_{\mathrm{HV}}$ was correlated with the VWC of wheat and corn at L-band. The backscattering coefficient $\sigma_{\mathrm{HV}}$ increases over vegetated areas, where the interaction with stems, branches, and leaves leads to a significant depolarization of the radar signal [34]. Due to its large vegetation volume scattering component, $\sigma_{\mathrm{HV}}$ can be used effectively in isolating the water content and structural characteristics of the vegetation canopy. However, although multisensor techniques gain more and more importance, few studies have compared active and passive microwave vegetation parameters at the global scale using space-borne data. Guerriero et al. [35] compared L-band backscattering coefficients and emissivity from theoretical simulations and airborne and space-borne experiments in the presence of different vegetation covers. Konings et al. [25] compared VOD to HV-backscattering and to the radar vegetation index (RVI) using three years of global Aquarius observations and found more scatter in the relationship between VOD and RVI than between VOD and the HV backscattering coefficient. This indicated the potential use of HV backscattering as a predictor for VOD. Still, that study included only a limited comparison between the variables.

In the present study, we further analyze the use of the crosspolarized backscattering coefficient $\sigma_{\mathrm{HV}}$ to provide an independent estimation as an alternative to optically derived VOD for the improvement of current radiometric soil moisture retrievals. We investigate the direct relationship of $\sigma_{\mathrm{HV}}$ and VOD on a global scale by using three years of collocated L-band radiometer and scatterometer measurements from the Aquarius/SAC-D satellite [14]. The relationships and the relative magnitude of the corresponding uncertainties are evaluated in terms of mean 
global patterns, regional biases, differences in dynamic range (seasonality amplitude), and phase-differences in seasons.

\section{DATA AND METHODS}

\section{A. Aquarius/SAC-D}

Aquarius was a joint mission of NASA and the Argentine Space Agency (Comisión Nacional de Actividades Espaciales, CONAE) that was designed primarily to obtain measurements for sea surface salinity retrievals. However, a land soil moisture product is also available [15]. The satellite was in a polar orbit with an altitude of $657 \mathrm{~km}$ and had a repeat orbit of seven days. It carried two instruments, a radiometer measuring at $1.413 \mathrm{GHz}$ and a scatterometer at $1.26 \mathrm{GHz}$, both arranged in a pushbroom configuration at three incidence angles: the inner beam at $28.7^{\circ}$, the middle beam at $37.8^{\circ}$, and the outer beam at $45.6^{\circ}$. This resulted in an overall swath width of $390 \mathrm{~km}$ with footprints consisting of ellipses with principal axis dimensions of $76 \times$ $94,84 \times 120$, and $96 \times 156 \mathrm{~km}$ for the inner, middle, and outer beam of the scatterometer, respectively, while the radiometer half-power footprints were slightly smaller [14]. The satellite delivered multiyear observations spanning June 2011 to June 2015.

This study uses three years of Aquarius level 2 backscattering coefficients, version 2.0, from September 2011 to August 2014. Delivered with the product is land surface temperature from the National Centers for Environmental Prediction (NCEP) Global Data Assimilation System, which is interpolated to the exact time and location of the Aquarius observations.

The NCEP land surface temperature and backscattering coefficients in $\mathrm{HV}$-polarization were gridded on a footprint scale with a modified sampling approach. Only observations from the middle beam $\left(37.8^{\circ}\right)$ are used, which is closest to the $40^{\circ}$ angle of SMAP, so that the results of this study can potentially be adopted for that mission. The first seven days of data were used to define a grid and all subsequent observations with centers less than $0.22^{\circ}$ away from a grid point are assigned to this grid point. In some cases this leads to the inclusion of some observations in multiple grid cells (this accounts for less than $1 \%$ of the observations), while observations that are not within this distance to a grid point are excluded from the study. More detailed information on the gridding scheme can be found in Konings et al. [25], McColl et al. [35], and Piles et al. [34].

\section{B. VOD From Dual-Channel Multitemporal Algorithm}

In this study, we relate the Aquarius backscattering coefficients to VOD derived from radiometer measurements. VOD $\mathrm{MT}_{\mathrm{T}}$ is estimated from dual-polarized level 2 Aquarius brightness temperatures, using the multitemporal algorithm of Konings et al. [25] (MT-DCA). The same gridding scheme as for backscattering coefficients was applied for the middle beam brightness temperatures.

The algorithm makes use of the slow-time dynamics of vegetation. It is based on the assumption that relative to soil moisture, VOD does not change significantly between several consecutive overpasses. Therefore, $N=2$ overpasses, with every overpass consisting of observations in two polarizations $p=\mathrm{H}, \mathrm{V}$, are combined within a moving window to simultaneously estimate a single VOD and two soil dielectric constants $k$, one corresponding to each overpass.

NCEP land surface temperature was used to normalize the brightness temperatures (into emissivity). The retrieval algorithm minimizes the difference between observed and modeled polarized emissivity $e_{p}$ to determine the vector of unknown parameters $\mathrm{X}$, containing VOD and $N * k$, corresponding to $k$ for $N$ consecutive overpasses:

$$
\min _{X=\mathrm{VOD}, k_{1}, \ldots k_{N}} J(X)=\sum_{t=1}^{N} \sum_{p=H, V}\left(e_{p}^{\text {obs }}-e_{p}^{\text {model }}(X)\right) .
$$

Konings et al. [24] found that the optimal choice for $N$ is the minimum value such that $2 * N$ observations provide enough information to determine $N+1$ parameter. A higher number of $N$ would increase the number of measurements available for the retrieval, but would also increase the probability of violating the assumption that VOD is constant across the $N$ overpasses. For the retrieval of the $\mathrm{VOD}_{\mathrm{MT}}$ from Aquarius observations, Konings et al. [25] used $N=2$, so that a total of four multipolarized observations are used. Konings et al. [25] give a detailed analysis on the quality of $\mathrm{VOD}_{\mathrm{MT}}$.

\section{SMOS Product}

The SMOS level 2 product, version 551, is used for a comparison to multitemporal $\mathrm{VOD}_{\mathrm{MT}}$. Changes to the $\mathrm{VOD}_{\mathrm{SMOS}}$ product are currently (and continually) under investigation. The version 620 has been in operations since May 2015 but the whole SMOS period will only be available after the next reprocessing campaign. The SMOS product contains soil moisture and VOD, which are retrieved by the level 2 processor from the level 1 product brightness temperatures [19]. The SMOS level 2 processor is based on an iterative minimization of the weighted squared differences between observed and modeled brightness temperatures, using the L-band microwave emission of the biosphere (L-MEB) [37] as forward model.

Multi-angular and dual-polarized brightness temperatures are simulated by L-MEB and a cost function is minimized between simulated and measured brightness temperatures. The availability of a high number of different angles provides additional information to the inversion process and therefore allows for a more accurate solution of the cost function. Soil moisture and VOD can be retrieved in a two-parameter retrieval, if enough brightness temperature observations at varying incidence angles are available. Otherwise a one-parameter retrieval is attempted and only soil moisture is retrieved, while VOD is fixed to its initialization value. This starting value of VOD is retrieved from observations of the previous three days or calculated from the ECOCLIMAP LAI and the parameters $b^{\prime \prime}$ and $b$ ", which mainly depend on vegetation structure.

For this study, values with a data quality index $>0.1 \mathrm{~m}^{3} / \mathrm{m}^{3}$ and $\mathrm{Chi}^{2}$ showing the goodness of retrieval fit $<0.5$ and $>2.5$ were excluded from all analyses [38]. Both are delivered with the product. The level 2 product is delivered on the ISEA grid, which has a grid spacing of approximately $15 \mathrm{~km}$. For proper comparison to Aquarius VOD, circles with a radius of $0.5^{\circ}$ were defined around the Aquarius grid points, which approximately correspond to the size of the Aquarius footprint. SMOS optical 
depth values within these circles were averaged. A weighted average was used, where the weights were calculated according to the inverse of their distances from the center grid point.

\section{International Geosphere Biosphere Programme Land Cover Dataset}

For the evaluation of the $\sigma_{\mathrm{HV}}$ and $\mathrm{VOD}_{\mathrm{MT}}$ relationship dependence on vegetation type, the dominant land cover class of each Aquarius footprint was determined through the 2005 MODIS MCD12Q1 International Geosphere-Biosphere Programme (IGBP) product [39]. The product distinguishes among 17 land cover classes and has a spatial resolution of $500 \mathrm{~m}$. For this study, the IGBP data were resampled to the Aquarius grid by determining the dominant land cover class for each footprint [25], [34]. The segregation of the microwave data for vegetation through IGBP data is carried out for the six main land cover classes-forest, shrubland, woody savanna, savanna, grassland, and agriculture - that cover most of the IGBP grid points, for which $\mathrm{VOD}_{\mathrm{MT}}$ retrievals exist. Thereby, all IGBP forest categories, evergreen needleleaf and broadleaf, deciduous needleleaf and broadleaf, and mixed forests, have been aggregated into a single category. The same applies to open and closed shrublands.

\section{E. Transcom}

The IGBP land cover classifications are used to broadly distinguish between vegetation types but the same classification can appear distributed around the globe and in different climates. In order to examine the influence of vegetation types with consistent seasonality, the global land regions need to be segmented according to a classification with better contiguity. Beside IGBP we also use the 11 terrestrial Transcom (Atmospheric Tracer Transport Model Intercomparison Project) regions [40]. These regions were mainly derived for the analysis of terrestrial carbon exchange, which considers both vegetation type and seasonality. The classification is based on a $1^{\circ} \times 1^{\circ}$ land cover map and is delimited by climate zones. The advantage of this classification is that regions are spatially simple and enclose vegetation of similar seasonal structure; therefore, seasonal effects of VOD retrieval can be analyzed. For the use in this study, each Aquarius grid point was assigned to the Transcom region in which it is located. The 11 Transcom regions are: North America Boreal, North America Temperate, South America Tropical, South America Temperate, Northern Africa, Southern Africa, Eurasian Boreal, Eurasian Temperate, Tropical Asia, Australia, and Europe.

\section{RESUlTS AND DISCUSSION}

In this study, we aim to establish a relationship between $\sigma_{\mathrm{HV}}$ and VOD evident in global land L-band radiometry. We use the three years of Aquarius colocated backscatter and brightness temperature. A predictive model of the VOD based on the backscatter $\left(\mathrm{VOD}_{\mathrm{HV}}\right)$ is developed for future applications with high-resolution radar measurements. In this study, we test the model with VOD $\mathrm{V}_{\mathrm{SM}}$ and multitemporal VOD $\mathrm{VDT}_{\mathrm{MT}}$. The first step is the development of the $\sigma_{\mathrm{HV}}-\mathrm{VOD}$ relationship.

\section{A. Global Relationship for $\sigma_{H V}$ and VOD}

The radiometer-based VOD and the cross-polarization backscatter both depend on the VWC through the vegetation dielectric constant. Importantly, they also depend on the vegetation structural characteristics. In examining the relationship between $\sigma_{\mathrm{HV}}$ and $\mathrm{VOD}_{\mathrm{MT}}$, we segment the global data and three years of retrievals based on major vegetation-type classifications. The IGBP data are used as an indicator of differences in vegetation structure. This is possible, as the main geometric structure of vegetation is dependent on the type of vegetation. For example, forests have a high vegetation layer and consist of woody trunk, stems, and branches, as well as leaves. The height of the vegetation layer for grassland and cropland areas is lower and it mainly consists of leaves. The composition of the vegetation layer significantly affects the amount of volume scattering [41] and the degree of depolarization of the microwave signal [34]. However, the IGBP land cover product can only be used as a very generalized classification of vegetation structure, as there may be differences within one land cover class, for example, due to differences between different plant species or due to differences in the age of vegetation. This might in particular be true for the land cover class of agriculture, which includes a high number of species with very different vegetation structures, for example, corn, wheat, or rice.

Fig. 1 shows the joint density of VOD and $\sigma_{\mathrm{HV}}$ for six main land cover categories (same axes scales are used for comparison). VOD and $\sigma_{\mathrm{HV}}$ follow a similar correspondence regardless of the vegetation type. The different vegetation types cover different ranges of VOD and $\sigma_{\mathrm{HV}}$. There is no appreciable nonlinear correspondence evident in the relationship for different vegetation types to assume anything more parameterized than a linear form. The data pairs for different vegetation types span different dynamic ranges but all on the same linear axis. For forests (lower-right panel in Fig. 1), there is evidence of some curvature at higher and denser vegetation cover. Since vegetation attenuation and scattering dominate the surface contribution under such conditions and soil moisture retrievals are more uncertain, the VOD predictions here are less useful. As a result the more parsimonious linear model is retained.

The statistics of the linear correspondence between the data pairs of $\sigma_{\mathrm{HV}}$ and $\mathrm{VOD}_{\mathrm{MT}}$ are shown in Table I. The range of slopes for the different types of vegetation is 7.37, the maximum difference can be found for agriculture and shrubland. Therefore, they are comparable in a way that allows the aggregation of all vegetation types, leading to a maximum slope difference of 4.5. Moreover, when aggregated together for all vegetation types, about $80 \%$ of the variations in VOD are explained by $\sigma_{\mathrm{HV}}$. Statistics for single vegetation types have lower explained variance since each covers a smaller dynamic range of data. The combined data in the last row of Table I have the highest dynamic range and allow a more robust linear model fit.

The same vegetation classification can be found in disparate and even distant regions with different characteristics. For example, the agriculture classification may correspond to many different crop types at different stages of growth or even fallow. Finally, since segmentation of the data by vegetation type reduces the dynamic range of variables, the linear regression estimation is affected. To test the influence of temporal stability on the resulting relationships, we calculated the regres- 

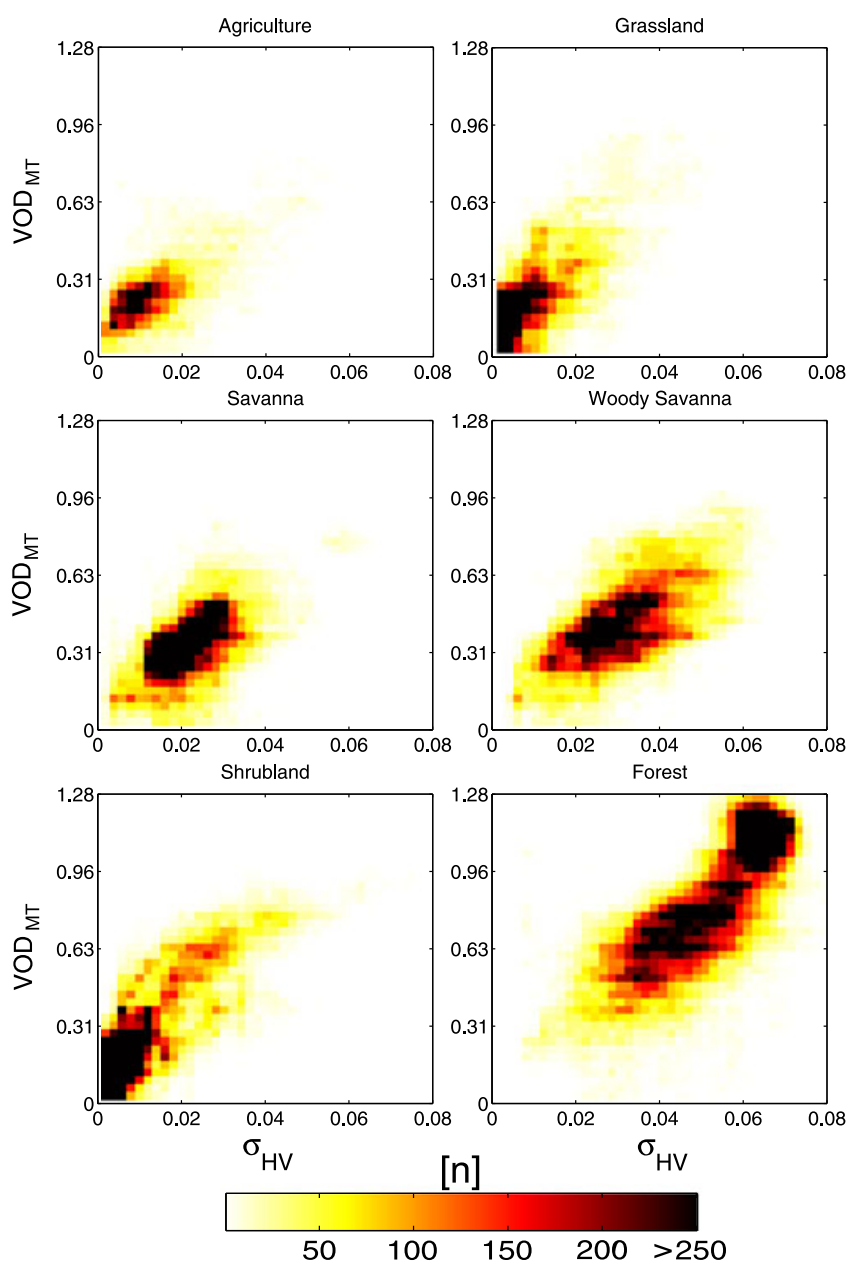

Fig. 1. Joint histograms of $\sigma_{\mathrm{HV}}$ and $\operatorname{VOD}_{\mathrm{MT}}$ for the major IGBP classes.

TABLE I

PARAMETERS (SLOPE AND INTERCEPT) AND COEFFICIENT OF DETERMINATION OF REGRESSION LINE FOR SEPARATE AND OVERALL IGBP CLASSES

\begin{tabular}{lrrrrr}
\hline \hline IGBP class & $\begin{array}{r}n \\
\text { Grid } \\
\text { points }\end{array}$ & $\begin{array}{r}n \\
\text { Observation } \\
\text { pairs }\end{array}$ & Slope & Intercept & $R^{2}$ \\
\hline Agriculture & 288 & 13620 & 9.19 & 0.16 & 0.41 \\
Grass & 505 & 29278 & 13.93 & 0.13 & 0.50 \\
Savanna & 277 & 42546 & 9.45 & 0.16 & 0.30 \\
Woody Savanna & 413 & 34828 & 9.66 & 0.17 & 0.42 \\
Shrubland & 878 & 54401 & 16.56 & 0.11 & 0.68 \\
Forest & 985 & 72156 & 14.99 & 0.09 & 0.62 \\
Overall & 3400 & 251692 & 14.02 & 0.11 & 0.79 \\
\hline \hline
\end{tabular}

Number of grid points and space-time observation pairs used for the regression are also shown.

sions separately for three month periods (September-November, December-February, March-May, June-August). Results reveal only low deviations for the different periods in all land cover classes (see Fig. 2).

The effect of vegetation structure on active and passive measurements is different, and vegetation type (including differences between species, age, biodiversity, etc.) influences the relationship [42]. However, the results in Table I show that land cover classification based on optical measurements (IGBP) is
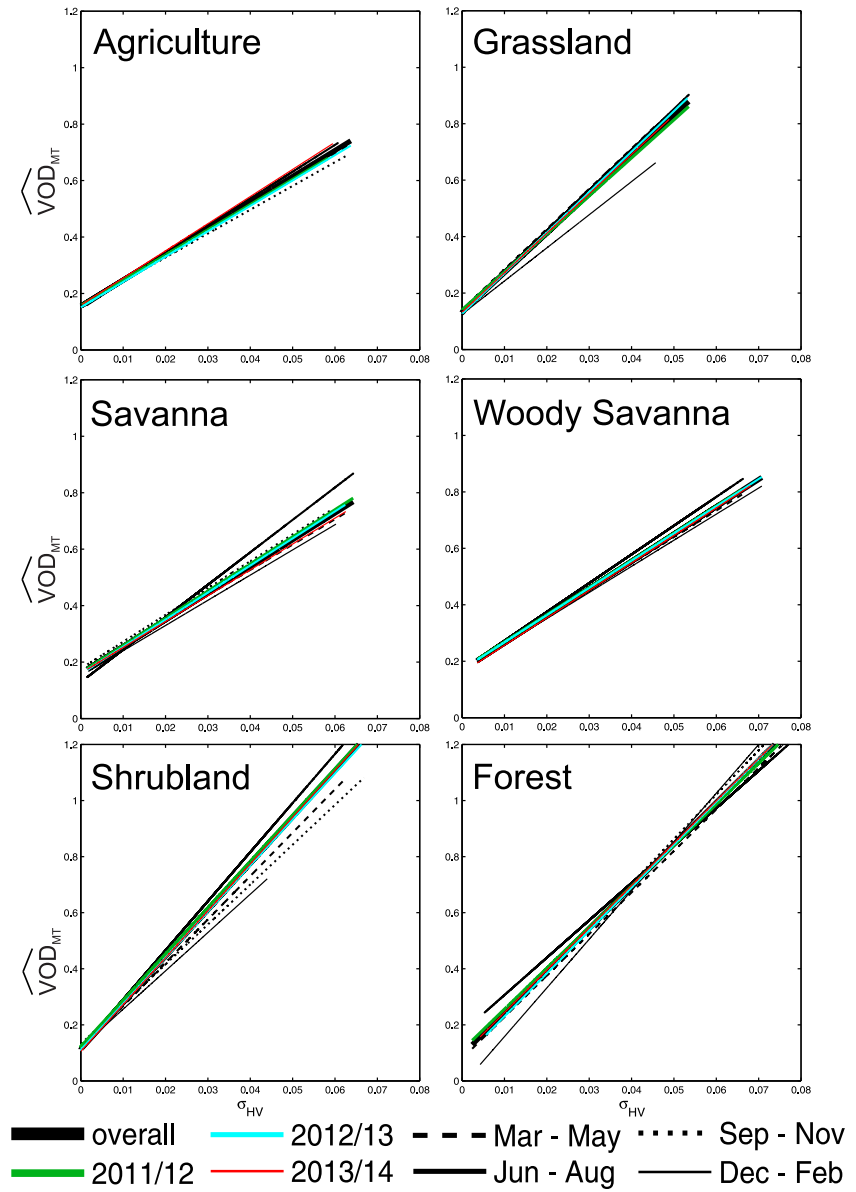

Fig. 2. Change of relationship of $\sigma_{\mathrm{HV}}$ and $\widehat{\mathrm{VOD}}_{\mathrm{MT}}$ for single years and three month periods separated by the major IGBP classes.

not the ideal way of segregating this influence, as the effects on the relative sensitivity to active versus passive microwave scattering vary at least as much within one land cover class as between them.

An advantage of using a global relationship independent of land cover and season is the possibility to characterize the role of vegetation in the active and passive microwave retrievals over land without any auxiliary data, as auxiliary data will always introduce its own error to VOD retrieval. In this study, we opt for removal of any dependence on additional data (vegetation classification and season) and combine the global $\sigma_{\mathrm{HV}}$ and $\mathrm{VOD}_{\mathrm{MT}}$ measurements going forward so that there is only one relationship between the data pairs.

A linear relationship between $\mathrm{VOD}_{\mathrm{MT}}$ and $\sigma_{\mathrm{HV}}$ in linear units is derived using all global grid points and all overpasses available. The equation of the linear relationship shown in Fig. 3 is given by

$$
\mathrm{VOD}_{\mathrm{HV}}=\widehat{\mathrm{VOD}}_{\mathrm{MT}}=14.02 \sigma_{\mathrm{HV}}-0.11
$$

with $\mathrm{VOD}_{\mathrm{HV}}$ being the VOD retrieved from $\sigma_{\mathrm{HV}}$ (linear power unit) and therefore corresponding to the estimator $\widehat{\mathrm{VOD}}_{\mathrm{MT}}$ of the regression function. The coefficient of determination $\left(R^{2}\right)$ is 0.79 for all grid points and all IGBP land cover classes jointly. 
[n]

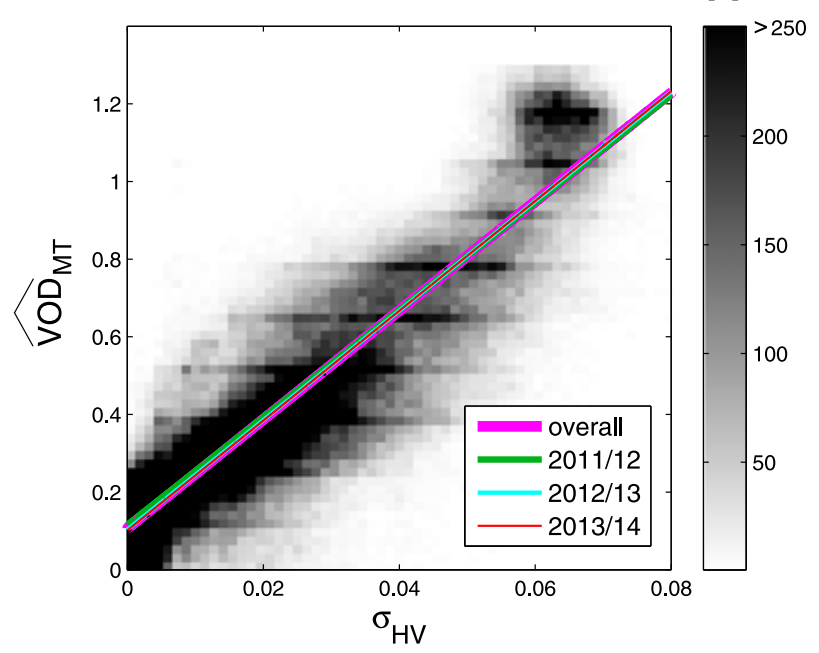

Fig. 3. Linear model of $\sigma_{\mathrm{HV}}$ and $\mathrm{VOD}_{\mathrm{MT}}$ for the complete study period and for individual years. Also shown is the joint histogram of $\sigma_{\mathrm{HV}}$ and $\mathrm{VOD}_{\mathrm{MT}}$ for all grid points.

The joint pdf function in the background of Fig. 3 shows that the regression function captures the relationship of $\sigma_{\mathrm{HV}}$ and $\mathrm{VOD}_{\mathrm{MT}}$, with the exception of the high value range.

Fig. 3 additionally shows the estimated linear relationships for individual years of the study period. They are all consistent with the linear relationship obtained for the full period indicating robustness of the relationship and temporal stability of the correspondence.

The linear functional form is limited and a better fit may be found through nonlinear functions. In this preliminary study, we choose the linear function for the initial exploration of the $\sigma_{\mathrm{HV}}$ and $\mathrm{VOD}_{\mathrm{MT}}$ relationship as we found that polynomials of a higher degree will not increase the $R^{2}$ values of $\sigma_{\mathrm{HV}}$ and $\mathrm{VOD}_{\mathrm{MT}}$. More complicated functions may be used, but the shape and parameters of that function need justification. In the future, numerical models of active and passive microwave interactions with the canopy can be used to enlighten the form of the nonlinear function. A physic-based modeling of the investigated relationship might also lead to its more general and precise understanding. In this data-driven study, the covariations in the data are studied using linear and first-order statistical models.

\section{B. VOD Derived From HV Backscattering Coefficient-Comparison to the SMOS Product}

$\mathrm{VOD}_{\mathrm{HV}}$ is estimated from $\sigma_{\mathrm{HV}}$ using (2). It can now be compared with VOD derived from SMOS multi-angular retrievals $\left(\mathrm{VOD}_{\mathrm{SMOS}}\right)$ and Aquarius multitemporal retrievals $\left(\mathrm{VOD}_{\mathrm{MT}}\right)$. The global mean patterns, biases in the mean patterns, dynamic ranges, and temporal covariations are examined. Fig. 4(a)(c) shows the mean global pattern of $\mathrm{VOD}_{\mathrm{HV}}, \mathrm{VOD}_{\mathrm{MT}}$, and VOD $D_{\mathrm{SMOS}}$. Although $\mathrm{VOD}_{\mathrm{HV}}$ and $\mathrm{VOD}_{\mathrm{MT}}$ are related, (2) contains misfit errors and since we intend to arrive at a model that is applicable with high-resolution radar data, the comparison is within the scope of the analysis. Unfortunately, in situ VOD retrievals for validation are not available at this scale for independent validation. (a)
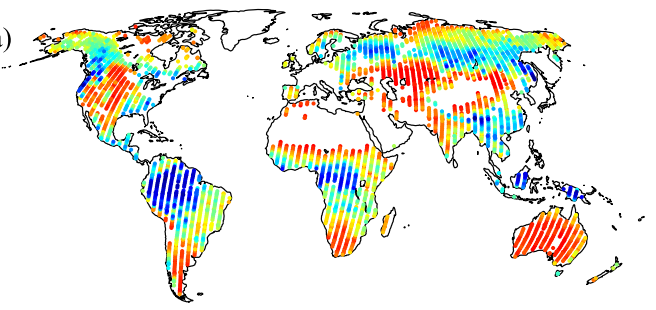

(b)
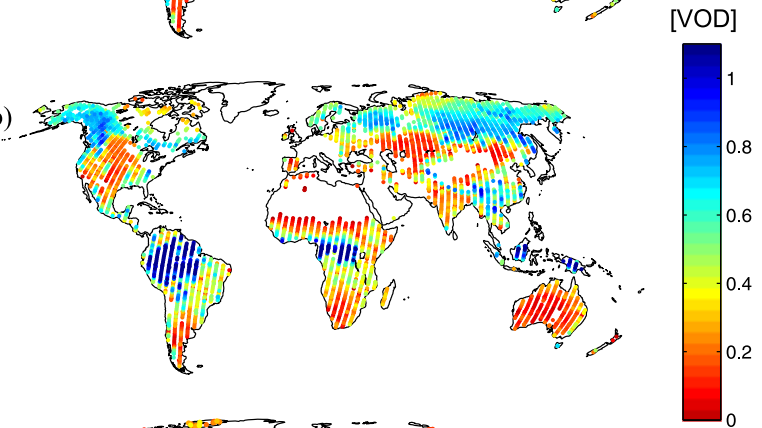

(c)
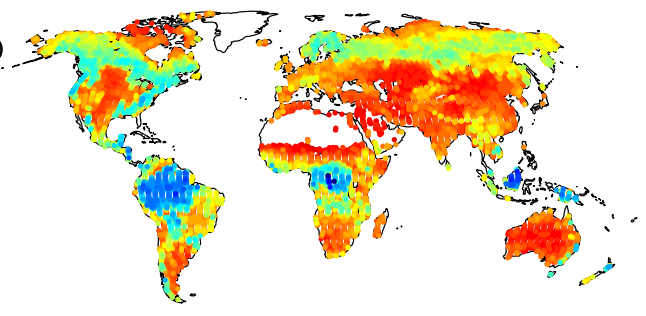

Fig. 4. Mean distribution of (a) $\mathrm{VOD}_{\mathrm{HV}}$, (b) $\mathrm{VOD}_{\mathrm{MT}}$, and (c) VOD $\mathrm{SMO}$.

The global maps of temporal-average VOD over the full study period show similar overall distribution of high and low values following the vegetation zones across the globe. VOD $\mathrm{DMOS}_{\mathrm{SM}}$ shows generally lower values than $\mathrm{VOD}_{\mathrm{HV}}$ and $\mathrm{VOD}_{\mathrm{MT}}$ as it will be shown in bias and dynamic range maps (forthcoming figure). The highest deviations amongst the three can be found in the northern parts of Asia and America, in particular in the North American and Eurasian boreal zones and in regions of tropical rainforests, in the South American tropical zone as well

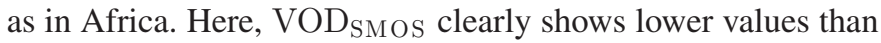
the others.

Differences between $\mathrm{VOD}_{\mathrm{SMOS}}$ and the two VODs derived from Aquarius observations can be partially explained by measurement differences of the different instruments. Although both radiometers measure in the same frequency, differences in radiometric sensitivity can lead to deviations in the measurements. Further differences are introduced by differences in spatial resolution of the two satellites. As the Aquarius footprint is quite large (approximately $100 \mathrm{~km}$ ), VOD $\mathrm{VD}_{\mathrm{SMS}}$ had to be upscaled for the comparison (see Section II-C). This procedure will introduce errors in the product. Furthermore, SMOS retrievals are only valid for the dominant land cover class of their respective pixels, while Aquarius values account for the whole area around the respective grid point. Discrepancies may, therefore, arise as a specific part of a pixel is not considered in $\mathrm{VOD}_{\mathrm{SMOS}}$, while it is included in the value of the Aquarius VOD. The use of different retrieval algorithms will also lead to discrepancies in the results.

The differences of $\mathrm{VOD}_{\mathrm{MT}}$ and $\mathrm{VOD}_{\mathrm{SMOS}}$ are more clearly illustrated in Fig. 5. Biases [see Fig. 5(a)] are mostly positive, indicating an underestimation of $\mathrm{VOD}_{\mathrm{SMOS}}$ as compared to 
(a)

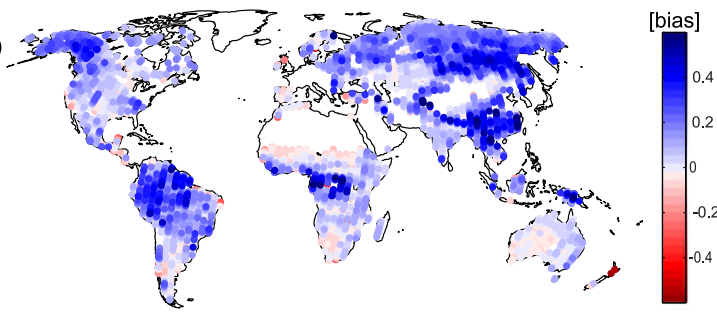

(b)

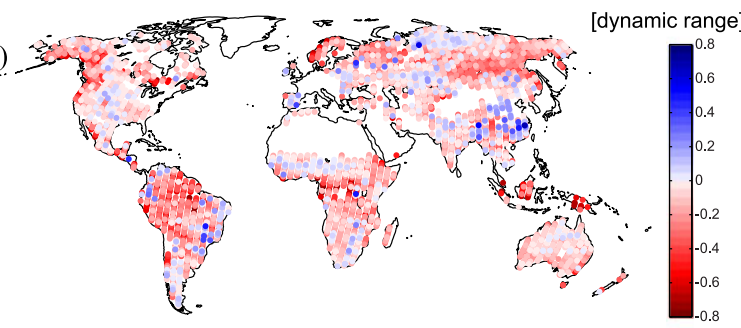

(c)

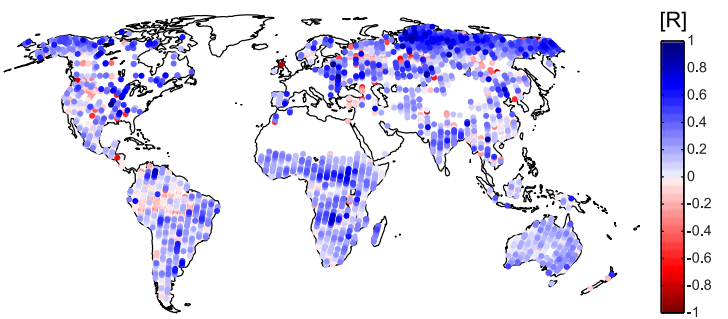

Fig. 5. Distribution of (a) mean bias of $\operatorname{VOD}_{\mathrm{MT}}$ to $\mathrm{VOD}_{\mathrm{SMOS}}$, (b) differences of dynamic range of $\mathrm{VOD}_{\mathrm{MT}}$ and $\mathrm{VOD}_{\mathrm{SMOS}}$, and (c) correlation coefficients of $\mathrm{VOD}_{\mathrm{MT}}$ and $\mathrm{VOD}_{\mathrm{SMOS}}$

$\mathrm{VOD}_{\mathrm{MT}}$. $\mathrm{VOD}_{\mathrm{SMOS}}$ is lower than $\mathrm{VOD}_{\mathrm{MT}}$ especially in tropical and boreal zones, which are dominated by dense forests. The highest bias values found in dense forests may be related to the loss of angular brightness sensitivity under these conditions. The angular separation of the polarized brightness temperature is reduced where there is dense vegetation. This separation is the basis for the estimation of VOD in the SMOS algorithm. It is, therefore, expected that the multi-angular approach and the multitemporal approach to VOD estimation diverge over densely vegetated regions. Nevertheless, the multitemporal approach to VOD estimation is also subject to possible errors over densely vegetated regions. If the canopy dominates the emission from the surface sufficiently, so that the observations are insensitive to soil moisture variations, the successive overpasses do not have any variability and do not add information to the retrieval above that of a single snapshot. The emissivity becomes high and the errors in ancillary land surface temperature information may also become amplified in the retrieval. Thus, the values of $\mathrm{VOD}_{\mathrm{SMOS}}$ and $\mathrm{VOD}_{\mathrm{MT}}$ should be interpreted with caution over densely vegetated regions. Nevertheless, Konings et al. [25] found that the dielectric constant retrieved simultaneously with $\mathrm{VOD}_{\mathrm{MT}}$ exhibited a clear seasonal cycle consistent with expected annual soil moisture dynamics over the Amazon. This suggests $\mathrm{VOD}_{\mathrm{MT}}$ is not severely hindered by low soil moisture sensitivity over many densely vegetated regions.

The differences of dynamic ranges for each grid point are shown in Fig. 5(b). In general, the differences tend to be neg- ative, indicating that the dynamic range of $\mathrm{VOD}_{\mathrm{MT}}$ is smaller than the dynamic range of $\mathrm{VOD}_{\mathrm{SMOS}}$. The highest differences can again be observed for the dense forests in the boreal and tropical zones. Overall, the differences are low, in particular for sparsely vegetated areas, for example in Australia. While the dynamic range is a measure of temporal amplitude of time series, correlation is a measure of phase correspondence. In Fig. 5(c), the correlation coefficients $(R)$ of $\mathrm{VOD}_{\mathrm{MT}}$ and $\mathrm{VOD}_{\mathrm{SMOS}}$ are displayed for each grid point with more than ten samples during the study period. Correlations of more than $75 \%$ of the grid points are positive and suggest similar seasonality in the two VOD estimates. More than $10 \%$ of the grid points even show a correlation higher than $R=0.5$. The exception is moist tropical Amazon, where short-time scale variations dominate seasonal changes.

\section{VOD Derived From HV Backscattering Coefficient-Errors of $\mathrm{VOD}_{H V}$ with Respect to $\mathrm{VOD}_{M T}$}

Even though $\mathrm{VOD}_{\mathrm{HV}}$ is related to $\mathrm{VOD}_{\mathrm{MT}}$ through (2), misfits in this relationship need to be quantified for its future applications to high-resolution radar data. The Aquarius multiyear data allow the estimation of error statistics for predicting VOD from radar measurements. The global mean patterns are similar [see Fig. 4(a) and (b)] and because of (2) the bias across all global values should be zero. However, it is important to map bias at geographical locations across the globe to examine the dependence of the bias on landscape and vegetation characteristics.

The differences between $\mathrm{VOD}_{\mathrm{HV}}$ and $\mathrm{VOD}_{\mathrm{MT}}$ are illustrated in Fig. 6(a), which shows the mean bias of $\mathrm{VOD}_{\mathrm{HV}}$ with respect to $\mathrm{VOD}_{\mathrm{MT}}$ for the full study period. Fig. 6(b) and (c) show the difference of dynamic ranges and temporal correlation, respectively.

In many regions, and especially in areas with low vegetation, the bias value is close to its global value of zero. This is the case, for example, in the temperate zone of North America, in Australia, and wide areas of temperate Asia. There are, however, some regional patterns indicating the role of landscape and vegetation characteristics on the differences between VOD and $\sigma_{\mathrm{HV}}$. In highly forested regions such as the North American and Eurasian boreal zones and in the South American and African tropical rainforests, bias with values around -0.2 shows an underestimation of $\mathrm{VOD}_{\mathrm{HV}}$ compared to $\mathrm{VOD}_{\mathrm{MT}}$. When compared to the mean values over these regions (see Fig. 1), this corresponds to $10-20 \%$ underestimation. This is consistent with the curvature away from linear evident for the VOD $-\sigma_{\mathrm{HV}}$ relationship in dense forests (Fig. 1 lower-right panel and Fig. 3 at the upper-right corner). This is caused by the effect of saturation of $\sigma_{\mathrm{HV}}$ in the presence of dense biomass over a certain threshold depending on frequency [42]. Furthermore, in these regions where trees form mainly vertical cylinders, $\sigma_{\mathrm{HV}}$ may be low due to double bounce effects, which cause less signal depolarization compared to multiple scattering [33]. This effect is lowered through crown attenuation at L-band, but still might influence the results by underestimating VOD in forests. This should be the subject of follow-on numerical simulation studies where combination of lossy-dielectric discs and cylinders is 
(a)

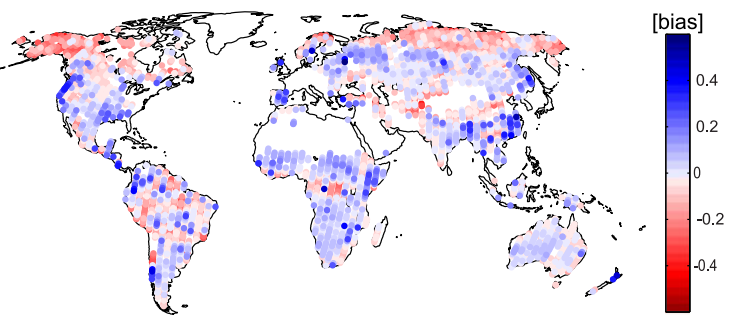

(b)
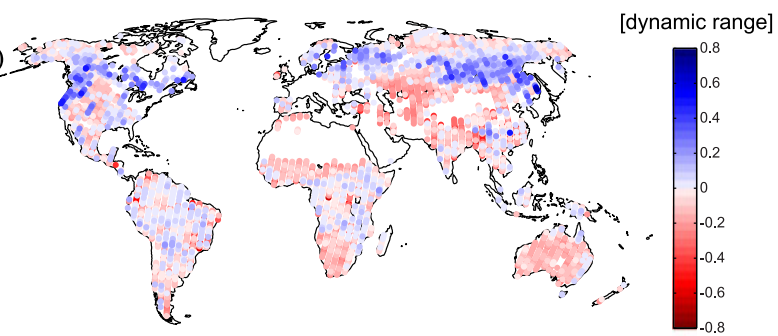

(c)
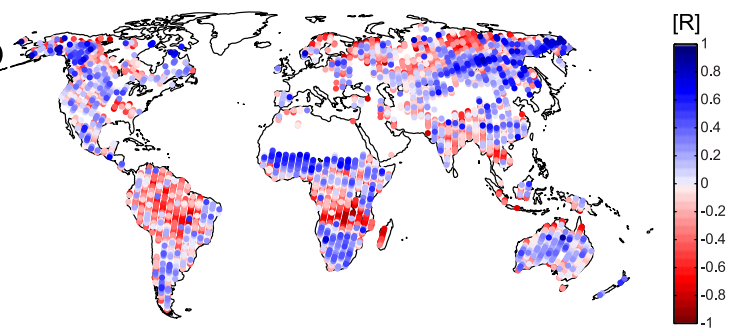

Fig. 6. Distribution of (a) mean bias of $\mathrm{VOD}_{\mathrm{HV}}$ to $\mathrm{VOD}_{\mathrm{MT}}$, (b) differences of dynamic range of $\mathrm{VOD}_{\mathrm{HV}}$ and $\mathrm{VOD}_{\mathrm{MT}}$, and (c) correlation coefficients of $\mathrm{VOD}_{\mathrm{HV}}$ and $\mathrm{VOD}_{\mathrm{MT}}$

used to estimate multiple scattering in idealized characterization of vegetation canopies.

The temporal mean or mapped patterns may be very similar based on the estimation in (2), yet if the seasonal amplitude of $\sigma_{\mathrm{HV}}$ is too high or too low or shifted in time, the estimated $\mathrm{VOD}_{\mathrm{HV}}$ seasonal cycle may be affected. Fig. 6(b) shows the difference in the dynamic range, an indicator of the seasonal amplitude, between $\mathrm{VOD}_{\mathrm{MT}}$ and $\mathrm{VOD}_{\mathrm{HV}}$. Mostly, the differences are small. Slightly negative differences, indicating a higher dynamic range of $\mathrm{VOD}_{\mathrm{MT}}$, can mainly be found in lightly vegetated areas, in particular in the nonforested parts of Northern and Southern Africa and Australia. Positive differences, and therefore a higher dynamic range of $\mathrm{VOD}_{\mathrm{HV}}$, can be found for high vegetation. In the North American and Eurasian boreal forests, the differences even get largely positive. The dynamic range is mostly a measure of the seasonal amplitude. The difference in the phasing of the seasonality can be captured with the temporal correlation coefficient.

Fig. 6(c) shows the correlation coefficients of time series for each grid point with more than ten samples in the time series. High values of $R$ can be found across most of the globe, which is indicative of phase consistency. Negative values, which indicate an out-of-phase relationship, can be observed for tropical and polar regions. VOD derived from passive microwave measurements (radiometer) is a function of attenuation of the signal as it crosses the vegetation canopy. It is mostly sensitive to the VWC and the above-ground biomass of the vegetation canopy. Since the wavelength of L-band $\lambda_{L}$ is $21 \mathrm{~cm}$, canopy elements with dimensions $\ll \lambda_{L}$, such as leafs and small branches (depending on species), are mostly transparent, and the main contributions come from large branches and stems [2]. The cross-polarized backscatter $\sigma_{\mathrm{HV}}$, however, is affected by the interaction with the woody biomass (tree trunks, branches, and stems) as well as the leafy biomass. In regions where the plant phenology is characterized by leaf-drop (senescence in boreal forests) or seasonal water-loss (monsoonal tropical forests), the VOD and $\sigma_{\mathrm{HV}}$ can be out-of-phase. This behavior is also observed in [25]. As discussed in [44], differences in sensitivity to woody and leafy biomass between $\mathrm{VOD}_{\mathrm{MT}}$ and $\sigma_{\mathrm{HV}}$ may lead to the observed anticorrelation, possibly due to dry season bud break and leaf flushing, or the persistence of leaf litter into the dry season. These differences between active and passive measurements suggest they may provide distinct but complementary information about tropical forest dynamics, and will be the specific focus of upcoming studies.

The influence of vegetation and climate on the phase correspondence and differences between $\mathrm{VOD}_{\mathrm{MT}}$ and $\sigma_{\mathrm{HV}}$ (and hence $\mathrm{VOD}_{\mathrm{HV}}$ ) is also evident in the seasonal pattern of biases when separately estimated for major vegetation and climate classifications. The biases between $\mathrm{VOD}_{\mathrm{HV}}$ and $\mathrm{VOD}_{\mathrm{MT}}$ for the main Transcom classes are contained in Table II. Table II also includes the biases as a function of season (MAM, JJA, SON, and DJF months groupings, as well as for the full study period) for each Transcom class. The lowest study period bias values with magnitudes between -0.02 and 0.02 are obtained for Australia, where wide areas are lowly vegetated desert areas, for Europe, and for all temperate regions, namely the North American, South American, and Eurasian. These areas have in common, that they contain moderate vegetation cover with a mixture of forests, low vegetation and agriculture. Regions containing tropical rainforests such as Tropical Asia and Northern and Southern Africa show biases with magnitudes of 0.050.06. An exception is the South American tropical region, which shows a negative bias of -0.03 . Highest (negative) study period bias values with magnitude of -0.10 and -0.14 can be found for the mainly forested regions of North American and Eurasian boreal zones, confirming the underestimation of $\mathrm{VOD}_{\mathrm{HV}}$ compared to $\mathrm{VOD}_{\mathrm{MT}}$ in the boreal regions.

Table II additionally shows the biases of $\mathrm{VOD}_{\mathrm{HV}}$ and $\mathrm{VOD}_{\mathrm{MT}}$ for the three month periods to examine the seasonality or phase differences. The overall global results do not differ much from the biases of the full study period, with deviations of 0.02 or less for the single three-month-periods. However, these values are aggregated over different climate zones and hemispheres, and therefore do not reflect a true seasonality.

The difference between the annual and single seasonal biases is not higher than 0.05 for any of the regions and seasons. This implicates that changes between negative and positive biases only appear for Transcom regions with low annual biases. The only exception is Europe with a deviation of 0.1 from the annual bias in winter. Only few seasonal patterns of increasing and decreasing biases can be found for comparable regions.

The North American and Eurasian boreal regions both show relatively low negative biases for the spring period (MAM) compared to their study period biases, and higher negative values for the summer period (JJA). However, while in the Eurasian region bias decreases again in fall $(\mathrm{SON})$, it increases in the 
TABLE II

Bias Between VOD M $_{\mathrm{t}}$ And VOD $\mathrm{D}_{\mathrm{h}}$ For the Full Study Period and Three Month Periods for Each Transcom Region

\begin{tabular}{|c|c|c|c|c|c|c|c|}
\hline Transcom region & $n$ Grid points & $n$ Observation pairs & Mar.-May & Jun.-Aug. & Sep.-Nov. & Dec.-Feb. & Study period \\
\hline NA boreal & 245 & 7746 & -0.10 & -0.14 & -0.15 & - & -0.14 \\
\hline NA temperate & 294 & 14053 & 0.00 & 0.01 & 0.02 & 0.02 & 0.02 \\
\hline SA tropical & 251 & 33568 & 0.00 & -0.04 & -0.08 & -0.04 & -0.03 \\
\hline SA temperate & 258 & 30725 & 0.01 & -0.01 & -0.02 & 0.00 & -0.01 \\
\hline Northern Africa & 284 & 33685 & 0.06 & 0.08 & 0.07 & 0.04 & 0.06 \\
\hline Southern Africa & 277 & 35804 & 0.06 & 0.02 & 0.04 & 0.10 & 0.05 \\
\hline Eurasian boreal & 677 & 18059 & -0.05 & -0.11 & -0.06 & - & -0.10 \\
\hline Eurasian temperate & 482 & 27266 & -0.04 & -0.01 & 0.01 & -0.02 & -0.02 \\
\hline Tropcial Asia & 116 & 13454 & 0.03 & 0.08 & 0.03 & 0.03 & 0.06 \\
\hline Australia & 219 & 28259 & 0.01 & 0.03 & -0.02 & 0.00 & 0.01 \\
\hline Europe & 264 & 5994 & 0.05 & 0.02 & 0.01 & -0.08 & 0.02 \\
\hline Overall & 3367 & 248613 & 0.00 & -0.02 & -0.01 & -0.01 & -0.02 \\
\hline
\end{tabular}

Numbers of data points and space-time observation pairs of the full study period used in the estimation are also included.

North American boreal region. For the winter period (DJF), too few observations are available for calculating a mean bias. For both African regions, highest bias values can be found in summer (JJA for Northern Africa and DJF for Southern Africa) and lowest values can be found for the winter months. This may be due to the higher VWC in summer, which may increase $\mathrm{VOD}_{\mathrm{MT}}$ but not $\sigma_{\mathrm{HV}}$, and therefore leads to lower values of $\mathrm{VOD}_{\mathrm{HV}}$. Another possibility is the seasonally different influence of structural components of the plants, for example, an increase of leaves during summer season, on the active and passive microwave signals. The two tropical regions in South America and Asia show relatively high seasonal fluctuations, but also no comparable patterns. Very low seasonal deviations of 0.02 or less from the annual bias but no distinct seasonal patterns can be found for all temperate regions. Table II shows that the use of only one relationship without any temporal discrimination leads to relatively low errors, with the exception of some seasons for specific Transcom regions.

\section{CONCLUSION}

This study presents a data-driven examination of the relationship between L-band backscatter $\left(\sigma_{\mathrm{HV}}\right)$ and VOD based on attenuation of land L-band emission from three years of Aquarius/SAC-D coincident active and passive microwave observations. A global relationship over all land cover classes and the complete study period is robust and temporally stable. Using a land-cover specific regression between $\mathrm{VOD}_{\mathrm{MT}}$ and $\sigma_{\mathrm{HV}}$ reduces the strength of the regression relationship relative to a global average, suggesting that land cover data cannot provide useful information about variability in vegetation scattering that is likely to influence the regression between $\mathrm{VOD}_{\mathrm{MT}}$ and $\sigma_{\mathrm{HV}}$.

The global relationship can be used for retrieving VOD from $\sigma_{\mathrm{HV}}$, with $\mathrm{VOD}_{\mathrm{HV}}$ being an estimator of $\mathrm{VOD}_{\mathrm{MT}}$. The relationship contains several sources of uncertainty, for example, the differences in the effects of the structural features of vegetation cover, and the relative magnitude of these uncertainties was analyzed by comparing $\mathrm{VOD}_{\mathrm{HV}}$ to $\mathrm{VOD}_{\mathrm{MT}}$. VOD $\mathrm{VO}_{\mathrm{HV}}$ has low bias with respect to $\mathrm{VOD}_{\mathrm{MT}}$ in areas with low vegetation density. In some high vegetation density regions, $\mathrm{VOD}_{\mathrm{HV}}$ is positively biased. However, the general spatial patterns between the two are quite similar. The differences of dynamic ranges and the correlation between $\mathrm{VOD}_{\mathrm{HV}}$ and $\mathrm{VOD}_{\mathrm{MT}}$ indicate high correspondence of temporal amplitude and phase for most regions. The main exception is over some tropical forests, where $\mathrm{VOD}_{\mathrm{HV}}$ and $\mathrm{VOD}_{\mathrm{MT}}$ are out-of-phase. This is possibly due to differences in sensitivity to leafy and woody biomass between backscatter $\sigma_{\mathrm{HV}}$ and VOD, which is related to the attenuation of the emitted surface brightness temperature as it crosses the vegetation canopy.

In this study, we also show that the $\mathrm{VOD}_{\mathrm{MT}}$ retrievals using the Aquarius/SAC-D pushbroom (single look angle but multitemporal) are consistent with the SMOS VOD retrievals based on the angular and polarization information available for the SMOS instrument.

Except for soil surface temperature information, the retrieval of $\mathrm{VOD}_{\mathrm{MT}}$ from the microwave radiometer does not need any ancillary data and corresponds to the status of the vegetation cover coincident with the time when soil moisture is being retrieved. However, as radars generally have a higher resolution than radiometers, linking the radiometer-based $\mathrm{VOD}_{\mathrm{MT}}$ to the cross-polarization backscatter $\sigma_{\mathrm{HV}}$ allows the estimation of $\mathrm{VOD}_{\mathrm{HV}}$ at higher resolution than the radiometer brightness temperature. This allows the investigation of vegetation heterogeneity influence on radiometer-based soil moisture retrieval, an effect that is considered to be one of the major sources of error in soil moisture retrieval. In this study, we establish a datadriven relationship between $\sigma_{\mathrm{HV}}$ and $\mathrm{VOD}_{\mathrm{MT}}$ and demonstrate that a linear relationship describes their joint distribution. We show that the additional information of land cover type does not increase the ability of the relationship to predict $\mathrm{VOD}_{\mathrm{HV}}$. However, results show differences in accuracy according to vegetation type. Further studies are needed to approach these issues, for example, with the use of regional regression equations in areas with high errors.

Numerical models of microwave (active and passive) interactions within the canopy need to be performed in order to inform the form of models used to relate cross-polarized backscatter and microwave attenuation. The numerical models characterize the woody biomass (trunks, branches, and stems) as lossy dielectric cylinders and leaves as disks. Combinations of cylinders and disks can be used to examine if the observed differences 
in backscatter-derived VOD and radiometer-derived VOD are due to the differences in the interactions of active and passive microwaves with these vegetation components.

\section{REFERENCES}

[1] E. Njoku and D. Entekhabi, "Passive microwave remote sensing of soil moisture," J. Hydrol., vol. 184, pp. 101-129, 1996.

[2] F. T. Ulaby, P. C. Dubois, and J. vanZyl, "Radar mapping of surface soil moisture," J. Hydrol., vol. 184, pp. 57-84, 1996.

[3] T. Mo, B. J. Choudhury, T. J. Schmugge, J. R. Wang, and T. J. Jackson, "A model for microwave emission from vegetation-covered fields," $J$. Geophys. Res., vol. 87, pp. 11229-11237, 1982.

[4] A. A. Van de Griend and M. Owe, "Determination of microwave vegetation optical depth and single scattering albedo from large-scale soil-moisture and nimbus smmr satellite-observations," Int. J. Remote Sens., vol. 14 , pp. 1875-1886, 1993.

[5] T. J. Jackson and T. J. Schmugge, "Vegetation effects on the microwave emission of soils," Remote Sens. Environ., vol. 36, pp. 203-212, 1991.

[6] A. A. Van de Griend and J. P. Wigneron, "The b-factor as a function of frequency and canopy type at h-polarization," IEEE Trans. Geosci. Remote Sens., vol. 42, no. 4, pp. 786-794, Apr. 2004.

[7] H. Lawrence et al., "Comparison between SMOS vegetation optical depth products and MODIS vegetation indices over crop zones of the USA," Remote Sens. Environ., vol. 140, pp. 396-406, 2014.

[8] Y. Y. Liu, R. A. M. de Jeu, M. F. McCabe, J. P. Evans, and A. I. J. M. van Dijk, "Global long-term passive microwave satellite-based retrievals of vegetation optical depth," Geophys. Res. Lett., vol. 38, 2011, Art. no. L18402.

[9] T. J. Jackson, et al., "Vegetation water content mapping using Landsat data derived normalized difference water index for corn and soybeans," Remote Sens. Environ., vol. 92, pp. 475-482, 2004.

[10] C. J. Tucker, "Red and photographic infrared linear combinations for monitoring vegetation," Remote Sens. Environ., vol. 8, pp. 127-150, 1979.

[11] J. C. Shi et al., "Microwave vegetation indices for short vegetation covers from satellite passive microwave sensor AMSR-E," Remote Sens. Environ. vol. 112, pp. 4285-4300, 2008.

[12] B. N. Holben, "Characteristics of maximum-value composite images from temporal avhrr data," Int. J. Remote Sens., vol. 7, pp. 1417-1434, 1986.

[13] S. C. Ahearn and C. deRooy, "Monitoring the effects of Dracunculiasis remediation on agricultural productivity using satellite data," Int. J. Remote Sens., vol. 17, pp. 917-929, 1996.

[14] D. A. Le Vine, G. S. E. Lagerloef, F. R. Colomb, S. H. Yueh, and F. A. Pellerano, "Aquarius: An instrument to monitor sea surface salinity from space," IEEE Trans. Geosci. Remote Sens., vol. 45, no. 7, pp. 20402050, Jul. 2007.

[15] R. Bindlish, T. Jackson, M. Cosh, T. J. Zhao, and P. O'Neill, "Global soil moisture from the Aquarius/SAC-D satellite: Description and initial assessment," IEEE Geosci. Remote Sens. Lett., vol. 12, no. 5, pp. 923-927, May 2015.

[16] D. Entekhabi et al., "The soil moisture active passive (SMAP) mission," Proc. IEEE, vol. 98, no. 5, pp. 704-716, May 2010.

[17] P. O'Neill, S. Chan, E. Njoku, T. Jackson, and R. Bindlish, "Soil moisture active passive (SMAP) - Algorithm theoretical basis document level 2 \& 3 soil moisture (Passive) data products," Jet Propulsion Lab., California Inst., Pasadena, CA, USA, JPL D-72550, 2014

[18] Y. Kerr et al., "The SMOS mission: New tool for monitoring key elements of the global water cycle," Proc. IEEE, vol. 58, no. 5, pp. 666-687, May 2010.

[19] Y. Kerr et al., "The SMOS soil moisture retrieval algorithm," IEEE Trans. Geosci. Remote Sens., vol. 50, no. 5, pp. 1384-1403, Apr. 2012.

[20] C. Montzka, J. Grant, H. J. H. Franssen, M. Drusch, and H. Vereecken, "A particle smoother with sequential importance resampling for radiative transfer parameter estimation," in Proc. 2013 IEEE Int. Geosci. Remote Sens. Symp., 2013, pp. 3431-3434.

[21] M. Owe, R. de Jeu, and T. Holmes, "Multisensor historical climatology of satellite-derived global land surface moisture," J. Geophys. Res.-Earth Surf., vol. 113, 2008, Art. no. F01002.

[22] W. Dorigo et al., "Evaluation of the ESA CCI soil moisture product using ground-based observations," Remote Sens. Environ., vol. 162, pp. 380$395,2015$.
[23] F. Tian et al., "Remote sensing of vegetation dynamics in drylands: Evaluating vegetation optical depth (VOD) using AVHRR NDVI and in situ green biomass data over west african sahel," Remote Sens. Environ., vol. 177, pp. 265-276, 2016.

[24] A. G. Konings, K. A. McColl, M. Piles, and D. Entekhabi, "How many parameters can be maximally estimated from a set of measurements?" IEEE Geosci. Remote Sens. Lett., vol. 12, no. 5, pp. 1081-1085, May 2015.

[25] A. Konings, M. Piles, K. Rötzer, K. A. McColl, S. Chan, and D. Entekhabi, "Vegetation optical depth and albedo retrieval using time series of dual-polarized L-band radiometer observations," Remote Sens. Environ., vol. 172, pp. 178-189, 2016.

[26] Y. Kim and J. J. van Zyl, "A time-series approach to estimate soil moisture using polarimetric radar data," IEEE Trans. Geosci. Remote Sens., vol. 47, no. 8, pp. 2519-2527, Aug. 2009.

[27] D. Singh, "Scatterometer performance with polarization discrimination ratio approach to retrieve crop soybean parameter at X-band," Int. J. Remote Sens., vol. 27, pp. 4101-4115, 2006.

[28] G. Satalino, L. Dente, and F. Mattia, "Integration of MERIS and ASAR data for LAI estimation of wheat fields," in Proc. 2006 IEEE Int. Geosci. Remote Sens. Symp., vols. 1-8, 2006, pp. 2255-2258.

[29] H. McNairn, J. Ellis, J. J. Van Der Sanden, T. Hirose, and R. J. Brown, "Providing crop information using RADARSAT-1 and satellite optical imagery," Int. J. Remote Sens., vol. 23, pp. 851-870, 2002.

[30] J. S. Chen, H. Lin, C. D. Huang, and C. Y. Fang, "The relationship between the leaf area index (LAI) of rice and the C-band SAR vertical/horizontal (VV/HH) polarization ratio," Int. J. Remote Sens., vol. 30, pp. 2149-2154, 2009.

[31] T. L. Rowlandson and A. A. Berg, "Errors associated with estimating vegetation water content from radar for use in passive microwave brightness temperature algorithms," Int. J. Remote Sens., vol. 36, pp. 782-796, 2015 .

[32] X. Jiao, H. McNairn, J. Shang, and J. Liu, "The sensitivity of multifrequency (X, C and L-band) radar backscatter signatures to bio-physical variables (LAI) over corn and soybean fields," in Proc. Int. Arch. Photogram. Remote Sens. Symp., Vienna, Austria, 2010, pp. 318-321.

[33] P. Ferrazzoli, S. Paloscia, P. Pampaloni, G. Schiavon, S. Sigismondi, and D. Solimini, "The potential of multifrequency polarimetric SAR in assessing agricultural and arboreous biomass," IEEE Trans. Geosci. Remote Sens., vol. 35 , no. 1, pp. 5-17, Jan. 1997.

[34] M. Piles, K. A. McColl, D. Entekhabi, N. Das, and M. Pablos, "Sensitivity of aquarius active and passive measurements temporal covariability to land surface characteristics," IEEE Trans. Geosci. Remote Sens., vol. 53, no. 8, pp. 4700-4711, Aug. 2015.

[35] L. Guerriero, P. Ferrazzoli, C. Vittucci, R. Rahmoune, M. Aurizzi, and A. Mattioni, "L-Band passive and active signatures of vegetated soil: Simulations with a unified model," IEEE J. Sel. Topics Appl. Earth Obs. Remote Sens., vol. 9, no. 6, pp. 2520-2531, Jun. 2016.

[36] K. A. McColl, D. Entekhabi, and M. Piles, "Uncertainty analysis of soil moisture and vegetation indices using aquarius scatterometer observations," IEEE Trans. Geosci. Remote Sens., vol. 52, no. 7, pp. 4259-4272, Jul. 2014.

[37] J. Wigneron et al., "L-band microwave emission of the biosphere (LMEB) model: Description and calibration against experimental data sets over crop fields," Remote Sens. Environ., vol. 107, pp. 639-655, 2007.

[38] K. Rötzer, C. Montzka, and H. Vereecken, "Spatio-temporal variability of global soil moisture products," J. Hydrol., vol. 522, pp. 187-202, 2015.

[39] M. A. Friedl et al., "Global land cover mapping from MODIS: algorithms and early results," Remote Sens. Environ., vol. 83, pp. 287-302, 2002.

[40] K. Gurney, R. Law, P. Rayner, and A. S. Denning, "TransCom 3 experimental protocol,” Dept. Atmos. Sci., Colorado State Univ., Fort Collins, CO, USA, Paper No. 707, 2000.

[41] C. Montzka et al., "Investigation of SMAP fusion algorithms with airborne active and passive L-band microwave remote sensing," IEEE Trans. Geosci. Remote Sens., vol. 54, no. 7, pp. 3878-3889, Jul. 2016.

[42] H. Vereecken, L. Weihermuller, F. Jonard, and C. Montzka, "Characterization of crop canopies and water stress related phenomena using microwave remote sensing methods: A review," Vadose Zone J., vol. 11, pp. 1-23, 2012.

[43] M. L. Imhoff, "Radar backscattering and biomass saturation: Ramifications for global biomass inventory," IEEE Trans. Geosci. Remote Sens., vol. 33, no. 2, pp. 511-518, Mar. 1995.

[44] A. Konings, "Microwave remote sensing of water in the soil - Plant system," Ph.D. thesis, Dept. Civil Environ. Eng., Massachusetts Inst. Technol., Cambridge, MA, USA, 2015. 


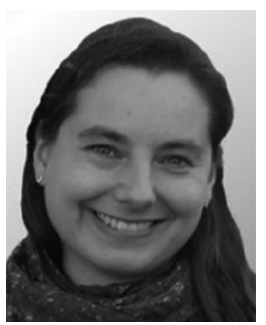

Kathrina Rötzer received the Diploma degee and the Ph.D. degree for geography and remote sensing from Ludwigs Maximilians University, Munich, Germany in 2010, and from the University of Bonn, Bonn, Germany, in 2016, respectively.

She is currently affiliated with the Institute of Bio- and Geosciences: Agrosphere (IBG-3), Forschungszentrum Jülich, Jülich, Germany. Since 2010, she has been working on active and passive microwave soil moisture remote sensing and was particularly involved in SMOS, SMAP, and ASCAT validation activities. Currently, her principal work is within the EU project eLTER. Her research interests include the retrieval of soil moisture, vegetation parameterization, and the analysis of soil moisture patterns.

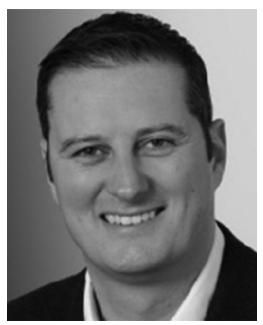

Carsten Montzka (M'17) received the Ph.D. degree in geography from the University of Bonn, Bonn, Germany, in 2007, for the integration of multispectral remote sensing data into nitrogen cycle simulations.

In 2004, he joined the Institute of Bio- and Geosciences: Agrosphere (IBG-3) of the Forschungszentrum Jülich, Jülich, Germany. Since 2007, he has been working on passive microwave retrieval for soil moisture and SMOS and SMAP validation activities. This includes modeling and upscaling of surface soil moisture, coupling hydrological models with microwave emission models, multiscale model calibration, and comparison with and integration of airborne remote sensing data. His current work has mainly been focused on the development of multiscale soil moisture data assimilation techniques within the Helmholtz-Alliance on "Remote Sensing and Earth System Dynamics" as well as on airborne active/passive microwave campaigns to support the soil moisture active-passive mission. Recently, he has been selected for the Arab-German Young Academy for Sciences and Humanities, Berlin, Germany.

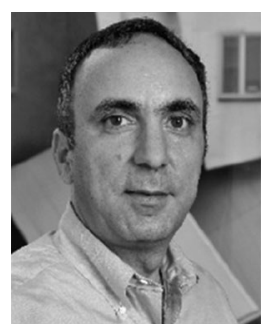

Dara Entekhabi (M'04-SM'09-F' 15) received B.S. (1983) and M.S. degrees $(1985,1988)$ in geography from Clark University, Worcester, MA and Ph.D. degree (1990) in civil and environmental engineering from the Massachusetts Institute of Technology (MIT), Cambridge, MA.

$\mathrm{He}$ is currently a Professor in the Department of Civil and Environmental Engineering and the Department of Earth, Atmospheric and Planetary Sciences, MIT. He is the Science Team Lead for the National Aeronautics and Space Administration's soil moisture active and passive mission that was launched January 31,2015 . His research interests include terrestrial remote sensing, data assimilation, and coupled landatmosphere systems modeling.

Dr. Entekhabi is also a Fellow of the American Meteorological Society and the American Geophysical Union. He is a member of the National Academy of Engineering.

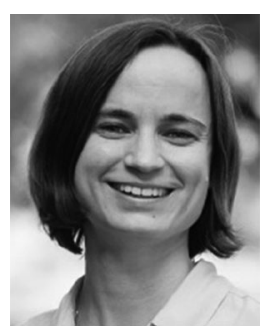

Alexandra G. Konings (SM' 12-M'16) received the B.S. degree in environmental engineering from the Massachusetts Institute of Technology, Cambridge, MA, USA, in 2009, the M.S. degree in environmental science from Dun University, Durham, NC, USA, in 2011, and the Ph.D. degree in hydrology from the Massachusetts Institute of Technology, in 2015.

Afterwards, she completed post-doctoral work at Columbia University, New York, NY, USA, and the NASA Jet Propulsion Laboratory, Pasadena, CA, USA. She is currently an Assistant Professor in the Department of Earth System Science, Stanford University, Stanford, CA, USA. Her primary research interests include microwave remote sensing and understanding water-carbon coupling at the land surface.

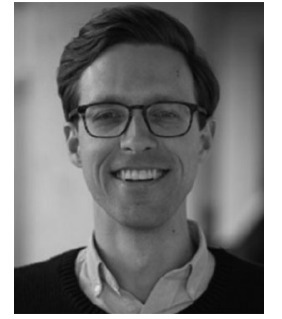

Kaighin A. McColl (S'09-M'10) received the B.Eng. (Hons.) degree in environmental engineering and the B.Sc. degree in applied mathematics from the University of Melbourne, Melbourne, Australia, in 2009, and the Ph.D. degree in hydrometeorology from the Massachusetts Institute of Technology, Cambridge, MA, USA, in 2016. His Ph.D. was supported by a National Science Foundation Graduate Research Fellowship.

$\mathrm{He}$ is currently a Ziff Environmental Fellow at Harvard University's Center for the Environment and Department of Earth and Planetary Sciences, Cambridge, MA, USA. His research interests include boundary-layer meteorology, land-atmosphere interactions, and remote sensing of soil moisture and vegetation.

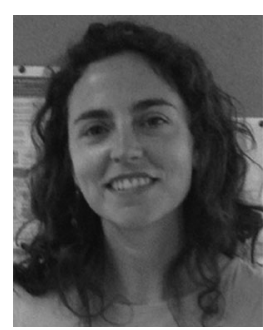

Maria Piles (S'05-M'11) was born in Valencia, Spain, in 1982. She received the M.S. degree from the Universitat Politècnica de València, València, Spain, in 2005, and the Ph.D. degree from the Universitat Politècnica de Catalunya (UPC), Barcelona, Spain, in 2010, both in telecommunication engineering.

In 2010, she joined the Department of Civil and Environmental Engineering, University of Melbourne, Melbourne, Australia, as a Research Fellow. From 2011 to 2015, she was a Research Scientist in the Department of Signal Theory and Communications, UPC. During these years, she was also a Research Affiliate in the Department of Civil and Environmental Engineering, Massachusetts Institute of Technology, Boston. In 2016, she joined the Institute of Marine Sciences, CSIC, as a Research Scientist. Since 2017, she has been in the Image Processing Laboratory, Universitat de València, as a "Ramón y Cajal" Senior Researcher. She has published 35 peer-reviewed journals papers, 3 book chapters, and more than 70 international conference presentations. Her research interest focuses on remote sensing for Earth observation, with special emphasis on microwave radiometers, radars and hyperspectral sensors, the retrieval of soil moisture and vegetation biogeophysical parameters, and the development of downscaling algorithms and data fusion techniques.

Dr. Piles is currently serving as the President of the IEEE Geoscience and Remote Sensing Society, Spanish Chapter. She received the Med-Storm Prize for Young Researchers in the European Geophysical Union Plinius Conference (2011) and the UPC Special Doctoral award in Information Technology and Communication (2012).

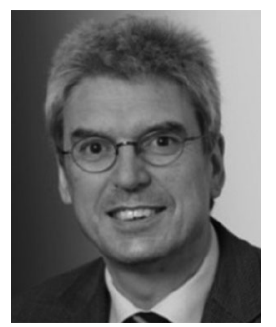

Harry Vereecken received the degree in agricultural engineering and the Ph.D. degree in agricultural sciences from the Katholieke Universiteit Leuven, Leuven, Belgium, in 1982 and 1988, respectively. His Ph.D. was on the development of pedotransfer functions to estimate soil hydraulic properties.

From 1988 to 1990, he was a Research Assistant on modeling nitrogen and water fluxes in soils and groundwater. From 1990 to 1992, he was a Researcher in the Institute of Petroleum and Organic Geochemistry, Forschungszentrum Jülich, Jülich, Germany, where, from 1992 to 2000, he became the Head of the Division "behavior of pollutants in geological systems." He was appointed the Director of the Institute of Agrosphere in 2000. His current field of research focuses on modeling of flow and transport processes in soils and hydrogeophysics. 